\title{
Analysis of Computer Teaching under Modern Educational Technology
}

\author{
Quanshui Lei \\ Southwest University of Science and Technology, Mianyang Sichuan, 621010, China
}

Keywords: modern educational technology; computer teaching; teaching mode.

\begin{abstract}
The wide application of information technology in educational field greatly promotes education modernization construction in China, and plays an important role in improving education quality of universities and colleges in China. Hence, during studying educational reform in the new period, it is required to focus on the application of modern educational technology, actively explore a new teaching mode by combining the application of modern educational technology and facilitate all-round improvement of education quality of universities and colleges. Starting from modern educational technology, this paper studies the reform of computer teaching mode so as to offer the strong support for comprehensive optimization of computer talent training.
\end{abstract}

\section{Introduction}

Through systematic research of modern educational technology, it is found that, the wide application of information technology and multimedia technology during promoting modern education reform has greatly facilitated optimal implementation of education activity and made teaching contents richer. The basic education form shows the features of flexibility and diversity. Information technology and multimedia technology play a very important role in promoting optimization of talent training. Therefore, for computer teaching, it is required start from the application of modern educational technology, actively explore reform and innovation of computer education mode, guarantee to manifest computer teaching advantages under the support of modern educational technology and lay a solid foundation for quality cultivation of computer specialty.

\section{Problems in traditional computer teaching mode}

Through systematic research and analysis of computer specialty teaching in China's universities and colleges, it is found that, due to the influence of traditional educational idea, college teachers of computer specialty do not cognize the importance of teaching reform in the process of carrying out computer teaching activity. In practical teaching process, they usually use the traditional teaching mode and ignore advanced teaching idea application and the exploration of scientific teaching method. As a result, students' subject status weakens in computer specialty teaching, and students seriously lack learning initiative and initiative, which seriously hinders cultivation of computer specialty accomplishment. Through systematic analysis of basic situations of college computer teaching in China, we can find that, teachers still use traditional cramming method, and the professional computer knowledge is still dominated by theoretical knowledge explanation, though there are some practical teaching activities. The author hopes to promote training of students' professional skills. In the teaching activity implementation process, teachers often organize students for practical operation in complete accordance with the textbook, which will restrict cultivation of students' computer specialty accomplishment and enhancement of their innovation ability. Besides, this is adverse to cultivating students into high-quality computer talents.

\section{Advantages of modern educational technology for computer specialty teaching}

The extensive application of modern educational technology plays a vital role for optimized development of computer specialty teaching, and greatly promotes improvement of computer specialty teaching quality and all-round optimization of talent training. So, during studying teaching 
reform for college computer specialty, it is required to start from the application of modern educational technology and strive to form a brand-new cognition of computer specialty teaching, guarantee the function of computer specialty teaching and facilitate optimized implementation of talent training.

Firstly, the extensive application of advanced educational technology in computer specialty teaching practice can properly expand and extend teaching contents, and generate the positive influence on teaching method reform. Computer teachers are no longer limited to classroom teaching activity, but extent teaching contents to network. They may cultivate students' active learning awareness through guiding them to independently learn relevant contents, promote students' improvement of learning ability and make sure students feel leaning joys in classroom teaching and actively explore computer knowledge. Based on promoting teaching quality improvement, the good conditions can be created for students' autonomous learning ability and innovation ability training ${ }^{[2]}$.

Secondly, reasonable application of modern educational technology in computer specialty teaching can facilitate the transformation of classroom teaching form. In other words, the teacher becomes the guide and assistant from the dominator. Students' dominant role is highlighted in the teaching activity. Students should be deemed as the center in both teaching activity design and teaching content selection. It is required to make sure the teaching activity adapts to students' growth state. Meanwhile, traditional computer specialty teaching objective will change under the assistance of modern educational technology. The teaching ability no longer focuses on students' scores, but hopes to promote cultivation of their computer skills and computer knowledge application, really organically combine theory and practice and make them apply what they have learned in future work and make contributions to the development of computer cause in China.

Finally, through the extensive application of modern educational technology, teaching efficiency and teaching effect of computer specialty also strengthen obviously. Based on the interaction and exchange between teachers and students and among students, classroom atmosphere becomes more active, and students' ability can be also cultivated. Based on the discussion and exchange, students can handle relevant problems. Further, students' solidarity and cooperation ability can be trained, and teachers' teaching quality can improve. This also facilitate to give play to the function of computer specialty teaching ${ }^{[1]}$.

Based on the above, during reforming and innovating computer specialty teaching activity in the new period, it is required to correctly cognize the importance of computer specialty teaching, study and explore computer specialty teaching reform from the application of modern educational technology, strive to promote the development of modern educational technology and ensure stable implementation of computer talent training.

\section{Reform and innovation measures of computer specialty teaching mode by combining the application of modern educational technology}

It is found that, the application of modern educational technology in computer specialty teaching can facilitate construction of a brand-new teaching mode and gradual improvement of teaching quality, and plays a vital role for students' future development. Thus during reforming and innovating computer specialty teaching in the new period, the application of modern educational technology should be deemed as the object of study to explore the reform of computer specialty teaching. Next, computer specialty teaching mode is combined to discuss the reform of computer teaching under modern educational technology:

\subsection{Playing-based teaching mode with the support of multimedia technology}

Multimedia technology is a constituent part of modern educational technology. During applying multimedia technology in computer specialty teaching reform, multimedia classroom may be used to carry out teaching activity. Besides, multimedia technology and computer specialty teaching activity may be organically combined to enhance richness and image of teaching content so that students can form the more profound cognition of computer knowledge. Meanwhile, their computer specialty 
accomplishment can be cultivated. During applying multimedia technology in computer specialty teaching, multiple types of basic teaching modes have been summarized through practical exploration of teachers. Playing-based teaching mode is a typical form ${ }^{[4]}$. Under the playing-based teaching mode, the teacher applies multimedia technology in computer specialty teaching activity, show computer knowledge and relevant operations to students in the form video or picture so that students can enhance their understanding and cognition of computer knowledge through rich and colorful videos or pictures. This can make sure students' learning effect improves significantly. Based on the application of paying-based teaching mode, teachers can transform dull theoretical knowledge, and the teaching vitality and imagine improve obviously. This can not just enhance the attraction of teaching content to students and facilitate students' active exploration and research, but also let students form profound cognition of knowledge and skills in the progressive learning and exploration activities. Besides, students' comprehensive quality can be properly cultivated. Thus, this can generate positive influence on cultivation of students' computer specialty accomplishment.

\subsection{Interactive teaching mode based on combination of multimedia and LAN}

In computer teaching practice of regular universities and colleges, teachers apply modern educational technology to actively explore a brand-new teaching mode based on the combination of multimedia and LAN in order to promote cultivation of students' practical skill and ability and make sure they can engage in computer-related work after their graduation. The mode aims to facilitate the interaction between teachers and students, make sure students can explore relevant skills and techniques in the interaction and exchange and enhance the whole learning effect. During applying the interactive teaching mode based on the combination of multimedia and LAN, teachers should provide a computer for every student in the class, achieve remote control of students' computers via LAN, and simulate teaching activities and operation skills on students' computers to make sure their practical operation skills can be well trained. Meanwhile, teachers may organically combine computer technology with LAN technology and combine demonstration teaching with practical operation teaching. In this way, students will more profoundly cognize professional skills of computer and can improve learning efficiency ${ }^{[5]}$. Moreover, with the assistance of multimedia technology, teachers may send the teaching video to students, and students can complete off-line independent study after class. This can effectively train students' autonomous learning ability and enhance the learning efficiency. Under the interactive teaching mo based on multimedia and LAN, universities may construct the favorable network learning environment for students. In this way, the interaction and exchange among students and between teachers and students can be more frequent. In addition, students' subjectivity can be overall exerted. Especially because of optionality of interactive teaching, students can combine their conditions to rationally choose relevant teaching contents, and their abilities can be properly cultivated. This will generate the positive influence on students' in-depth learning of computer knowledge. Thus, based on the application of modern educational technology, it is required to enhance the application of interactive teaching mode based on the combination of multimedia and LAN and overall promote computer specialty teaching quality.

\subsection{Open simulation teaching mode based on internet resource}

In the era of internet, internet resource shows certain openness and sharing features. The open simulation teaching mode based on internet technology has great similarity with LAN teaching. But it can be found through systematic research that, the two have the differences in the essence. Seeing from practical teaching mode selection and teaching effect, although LAN teaching can be applied to manage students' computers with the help of remote control technology, the pertinence of teaching mode is stronger due to the limit of service scope, and there is the obvious limit in the aspect of teaching scope. So in order to improve teaching effect and provide high-quality teaching services for students, internet resources should be combined to actively explore the open simulation teaching mode, provide students with richer learning materials and means, expand and extend learning scope and facilitate students' systematic cognition of computer knowledge. In the meantime, to further enhance students' computer operation skills, teachers may choose simulation teaching tasks 
corresponding to students' learning ability on the basis of mining network resources and let students complete the tasks in vocational simulation scene. This can not just train students' operation skills, but also promote their accumulation of computer-related work experience and provide support and reference for their future computer-related work. The important function of internet teaching resource can be really exerted, and students' computer skills can be trained only through organically combining network resource with simulation laboratory teaching under the support of internet information technology. At the same time, students can apply what they have learned in future work and contribute to the development of computer industry.

\section{Conclusion}

In conclusion, the application of modern educational technology can provide the favorable support for optimization of computer specialty teaching and promote optimization of talent training quality. Therefore, it is required to start from the application modern educational technology, explore corresponding teaching reform measures, strive to form corresponding advantages in computer talent training, facilitate improvement of talent training quality, really cultivate students into the high-quality talents adapting to social demands and offer the good talent guarantee for the development of computer case and information communication case.

\section{References}

[1] Li Junwei, Exploration of Computer Teaching Mode under Modern Educational Technology, Wireless Internet Technology, 2017(9):87-88.

[2] Li Hong, Analysis of Computer Teaching Mode Based on Modern Educational Technology, Digital Subscribers, 2013(6):148-148.

[3] Xu Jie, Analysis of College Computer Teaching Mode Based on Modern Educational Technology, Computer CD Software and Applications, 2014(20):307-307.

[4] Guo Xinning, Exploration and Analysis of Computer Teaching Mode Based on Modern Educational Technology, Computer Knowledge and Technology: Academic Exchange: 2014(36):8708-8709.

[5] Lei Baojun, Analysis of Computer Teaching Mode Based on Modern Educational Technology, Heilongjiang Science and Technology Information, 2013(35):148-148. 